\title{
From the Editors' Desk: Peer Review at JGIM
}

\author{
Carol K Bates, $M D^{7}$, Jeffrey L Jackson, MD MPH' , and Steven Asch, MD MPH ${ }^{3}$
}

'Beth Israel Deaconess Medical Center, Harvard Medical School, Boston, MA, USA; ${ }^{2}$ Division of General Medicine, General Internal Medicine, Zablocki VA, Milwaukee, WI, USA; ${ }^{3}$ VA Center for Innovation to Implementation, Stanford Division of Primary Care and Population Health, Stanford, CA, USA.

$\mathrm{J}$ Gen Intern Med

DOI: $10.1007 / \mathrm{s} 11606-019-05389-6$

(c) Society of General Internal Medicine 2019

\section{A} s our recent authors and peer reviewers can attest, JGIM moved to Editorial Manager, a web-based platform, in April 2019. We are still on the learning curve, but we believe that the system will shorten the time from submission to acceptance. Integral to this is the management of peer review of submitted manuscripts. In our new system, reviewers are given four days to respond to an invitation. The system automatically generates invitations until three reviewers have agreed to review a manuscript. It is too early to really know if this will change our time to publication, but we are optimistic!

The basic tenets of our approach have not changed. The editors-in-chief continue to reject approximately $40 \%$ of all submissions without review. We continue to depend upon an extraordinary group of dedicated associate editors who take a closer look at the remaining manuscripts and manage the peer review process for the majority of our submissions. We also, of course, rely upon our peer reviewers.

While imperfect, peer review has been shown to improve the quality of manuscripts. ${ }^{1-4}$ Our authors appear generally grateful and most often say that they believe the process has improved their publications. We ask peer reviewers to identify scientific strengths and weaknesses and assess the likely impact on the field of general internal medicine. A poorly written article may dissuade the team from peer review even when scientifically sound. While we ask reviewers to make recommendations regarding acceptance, we often see a range of opinions from accept to reject on the same paper. We use these recommendations as only one element in what is ultimately an editorial decision. We are grateful to authors who continue to submit to the journal, understanding that we are striving to get it right.

JGIM would like to thank the many talented people who have volunteered their time to serve as peer reviewers for the journal over the past 12 months. In 2018, 19, 991 reviewers provided a total of 1227 reviews with a mean quality score of 4.6 on a scale of 1-6 (as judged by our JGIM associate editors). Of these, 224 provided at least two reviews, and 16 provided three or more. We are indebted to them for their service.
Among this group of dedicated peer reviewers, there is a group that stands out. These top peer reviewers performed at least two reviews between July 2018 and June 2019, returned all reviews within 30 days, and received a quality score of 4 or greater (out of a maximum score of 6 ) on all reviews. An asterisk identifies the 148 reviewers who meet these criteria. We congratulate them on their service to the academic community and thank them for their efforts on behalf of the journal. JGIM operates a single-blind model of peer review, and as such referees are not routinely asked to give consent to having their names shared. The previously published list of peer reviewers' names has been removed in line with data protection regulations (November 2021)

If you are not already registered as a peer reviewer, please consider signing up. If you are publishing in JGIM, you are benefiting from the service of your colleagues through this process. If each article is reviewed by 3 people that means that you should review 3 times as many papers as you submit! We look forward to working with all of our readers and reviewers in the year to come.

JGIM operates a single-blind model of peer review, and as such referees are not routinely asked to give consent to having their names shared. The previously published list of peer reviewers' names has been removed in line with data protection regulations (November 2021).

Corresponding Author: Carol K Bates, MD; Beth Israel Deaconess Medical Center, Harvard Medical School, Boston, MA, USA (e-mail: carol_bates@hms.harvard.edu).

\section{Compliance with Ethical Standards:}

Conflict of Interest: The authors declare that they do not have a conflict of interest.

\section{REFERENCES}

1. Goodman SN, Berline J, Fletcher SW, Fletcher RH. Manuscript quality before and after peer review and editing at Annals of Internal Medicine Ann Intern Med. 1994. 121(1):11-21.

2. Shattell MM, Chinn P, Thomas S, Cowling WR. Authors' and editors' perspectives on peer review quality in three scholarly nursing journals. J Nurs Scholarsh 2010. 42(1):58-65.

3. Wager E, Middleton P. Effects of technical editing in biomedical journals: a systematic review. JAMA. 2002;287:2821-4.

4. Roberts JC, Fletcher RH, Fletcher SW. Effects of peer review and editing on the readability of articles published in Annals of Internal Medicine. JAMA. 1994;272:119-2 